\title{
The influence of mains leakage and urban drainage on groundwater levels beneath conurbations in the UK
}

\author{
M. Price and D. W. Reed
}

Mr. G. F. Read, University of Manchester Institute of Science and Technology

In $\S 6$ it is suggested that $20-30 \%$ of mains water is unaccounted for. This seems low. The rate of leakage out of the water system amounts to an average of $30 \%$ with the figure rising to $40 \%$ and higher in individual areas. The Scottish Development Department, in an assessment of public water supplies published in 1984, stated that the total leakage in Scotland was just under $40 \%$.

39. The Authors referred to Victorian sewers and their role in the scenario. I had experience when City Engineer in Manchester, a city not unknown in the field of sewer dereliction and the related collapse problems. When a water main at a higher level leaks into the old Victorian sewer below-generally by a clearly defined path such as adjacent to a lateral connection-carrying with it ground particles, a cavity follows and in due course a typical sewer collapse takes place. It is never clear whether ground movement related to the derelict sewer causes the initial leakage.

40. The point made in the Paper about the old sewerage leaking is accepted but it would appear that much of the leakage of purified water continues along the sewerage network and eventually into a river or stream. Hence I would not entirely agree with the Authors' view that roughly a quarter of the water in public mains leaks back into the ground. Whether it be a third or a quarter, the water leaks into the ground initially but where there are defective sewers at a lower level, in certain instances much of it joins the flow in these rather than escapes into the ground generally.

41. I support the Authors' suggestion for the reduction of mains leakage in order to stop the current rise of the water table. It would also assist in reducing the collapse of Victorian sewers and all the related social costs involved, pending adequate funds being made available for sewerage rehabilitation.

\section{Mr Price and Dr Reed}

The Authors agree with $M r$ Read that the proportion of mains water unaccounted for may exceed $20-30 \%(\$ 11)$, but found difficulty in finding reliable figures for England and Wales. We were anxious not to overstate the case, particularly as some undertakings have begun active leakage control programmes.

43. Mr Read commented on Manchester's sewerage system. The Authors accept that sewers lie below water mains in many conurbations and are thus potentially capable of intercepting water leaking from mains. In poorly-permeable soils and rocks, such as those present beneath parts of Machester, they almost

Paper published: Proc. Instn Civ. Engrs, Part 1, 1989, 86, Feb., 31-39. 


\section{DISCUSSION}

certainly do so. In such places the mains leakage will result in the ground becoming locally saturated, so that the pore water pressure is greater than atmospheric pressure. However, these are not the areas which we were most concerned. We were seeking to show the changes in infiltration that have resulted from urbanization, and in poorly permeable areas there would have been little natural infiltration before urbanization. Major changes in water level in these areas will have been caused almost solely by variations in pumped abstraction; the situation is in many ways like that of London ( $\$ 31-32$ ).

44. In sandy soils and sandstones, sewers above the water table will be surrounded by porous permeable materials in which the pore water pressures are generally less than atmospheric; they will rise above atmospheric pressure as a result of leakage only in the vicinity of a large leak or where a layer of less permeable material gives rise to a perched groundwater body. In general, therefore, there will be no hydraulic gradient from the ground to the sewers to cause water to enter a sewer. In these circumstances, theory therefore predicts that leakage is more likely to occur from the sewer than into it.

45. Sewers below the water table will be able to intercept groundwater. However, this condition is not really relevant to the discussion on rising water levels.

46. The suggested link between mains leakage and sewer collapse (\$39) is a further reason for greater investment in leakage control programmes. Water undertakers have begun to make greater efforts to reduce leakage; although this is for reasons of economy and resource enhancement rather than for geotechnical reasons, it will be interesting to see whether there is a corresponding reduction in the rate of rise of groundwater levels. 